\title{
MÍDIA E IDENTIDADE - O REGIONAL NO JORNAL NACIONAL ${ }^{1}$
}

\author{
Nairo Luiz ORLANDI ${ }^{2}$ \\ Carolina Junqueira LOPES \\ Ângela Cristina Trevisan FELIPPI ${ }^{4}$ \\ Fabiana Quatrin PICCININ ${ }^{5}$
}

\section{RESUMO}

O artigo se propõe a discutir como o telejornal mais antigo e de maior audiência do Brasil, o Jornal Nacional, da Rede Globo de Televisão, constrói, por meio de suas notícias, a realidade brasileira e, desta forma, contribui para a construção de identidades sobre as distintas regiões do Brasil. Toma-se, particularmente, o caso das regiões do Rio Grande do Sul para um olhar mais atento. Compreende-se a construção de identidade na mídia como estreitamente relacionada aos processos de visibilidade pública e de construção de sentidos ofertados pelo jornalismo de televisão sobre as regiões e suas populações. No artigo, buscase estabelecer uma relação entre as implicações de determinada produção de sentidos e o processo de desenvolvimento. Tomam-se as teorias dos estudos culturais e da análise do discurso como base reflexiva para a discussão feita por meio de pesquisa bibliográfica.

Palavras-chave: Telejornal. Identidade cultural. Desenvolvimento Regional. Análise do discurso.

\section{ABSTRACT}

The article proposes to discuss how the oldest and most widely viewed Brazilian TV newscast, the Jornal Nacional, from Rede Globo de Televisão, constructs Brazilian reality through the news, and, in this way, contributes to the construction of the different regions of Brazil. It looks particularly at the regions of Rio Grande do Sul. It comprehends the identity construction in media as closely related to public visibility processes and construction of meanings offered by television journalism about regions and populations. It seeks to establish a relation between implications of a particular prodution of meanings and the

1 O artigo faz parte da pesquisa As representações da heterogeneidade regional do Rio Grande do Sul no Jornal Nacional, da Rede Globo, desenvolvida junto ao Programa de Pós-Graduação em Desenvolvimento Regional, da Universidade de Santa Cruz do Sul.

2 Graduado em Jornalismo na Universidade de Santa Cruz do Sul - UNISC/RS. Jornalista. E-mail: nairo.orlandi@atlantida.com.br. Bolsista (PROBIC/FAPERGS).

3 Graduado em Jornalismo na Universidade de Santa Cruz do Sul - UNISC/RS. Jornalista. E-mail: carolinajlopes@gmail.com. Bolsista (PROBIC/FAPERGS).

4 Professora do Programa de Pós-Graduação em Desenvolvimento Regional e do Departamento de Comunicação Social da Universidade de Santa Cruz do Sul - UNISC/RS; Doutora em Comunicação Social, bolsista do Fundo de Apoio à Pesquisa da UNISC. E-mail: angelafe@unisc.br

5 Professora do Programa de Pós-Graduação em Letras e do Departamento de Comunicação Social da Universidade de Santa Cruz do Sul - UNISC/RS; Doutora em Comunicação Social; bolsista do Fundo de Apoio à Pesquisa da UNISC. E-mail: fabi@unisc.br 
development process. The cultural studies theory and analysis of speech were taken as basis for reflective discussion by means of literature.

Keywords: TV newcast. Cultural identity. Regional development. Analysis of speech.

\section{INTRODUÇÃO}

Os processos de globalização acentuaram os debates teóricos em torno da questão da identidade cultural. A intensificação das migrações dos povos pelo planeta, dos negócios transnacionais, do alcance sem precedentes das trocas informacionais e comunicacionais via mídia alteraram o panorama das identidades culturais, levando também o campo acadêmico a se dedicar com mais vigor a essas questões.

Identidade cultural é uma construção social, que se dá na relação que um indivíduo estabelece com outro, quando vai assumindo ou rechaçando certas características dadas pelo outro/coletividade, através de categorias compartilhadas. É também um discurso, mas um discurso que vem de uma prática social e que, por sua vez, também a constitui. Identidade, então, está em permanente construção, nunca acabada, sofrendo ação da história.

A compreensão da identidade cultural, nessa perspectiva, a dos estudos culturais, tem que ser visada a partir do conceito de cultura. Cultura seria uma estrutura de significados compartilhados incorporados em formas simbólicas - a linguagem - por meio das quais os indivíduos se comunicam. Identidade, um discurso sobre si mesmo ou sobre o grupo na interação com os outros, que só é possível por meio de uma estrutura de significados comuns e da linguagem. Estudar identidade é estudar como as formas simbólicas são mobilizadas para sua construção (LARRAIN, 2003, p. 32). "Cultura é ordinária", diz Williams (1993, p.1). É o modo de vida de um povo e os significados comuns atribuídos por ele à realidade; é a descrição das práticas de atividade intelectual e artística, mas também os processos de descoberta e criação; e é o processo de desenvolvimento mental.

Para Hall (1997), é inegável a importância sem precedentes que a cultura assumiu, no sentido de propiciar o desenvolvimento de processos econômicos e políticos através das tecnologias da informação. E também a cultura tornou-se importante no aspecto econômico, dada a expansão das indústrias culturais, dos meios de produção e de circulação culturais. O melhor exemplo é o da mídia, que, além de ser um dos principais meios de circulação de informações, idéias e imagens pelo planeta, é um setor econômico dos mais importantes, não só pelo seu capital e pelo volume de recursos que faz circular, mas como sustentáculo de trocas econômicas globais. Cultura não é uma esfera autônoma, interfere e é afetada pelos processos econômicos, sociais e políticos.

O movimento da globalização na cultura interferiu na produção, circulação e consumo de bens culturais, criando uma cultura global (ORTIZ, 1994). Para Hall (2003), há dois processos opostos funcionando atualmente com a globalização, um formado por forças dominantes de homogeneização cultural, que detêm o domínio do mercado cultural, e ameaça homogeneizar a cultura. Por outro lado, sem o poder de confrontar as primeiras, estão forças que vão disseminando as diferenças culturais pelo globo, que não subvertem a ordem dominante, mas vão negociando com ela. É a "proliferação subalterna da diferença" (2003, p. 60). Como o mercado global depende do novo, dessas diferenças, inclusive num processo que Hall (1999) denomina de mercantilização da etnia, ele as vai assimilando. E isso 
é feito através da comunicação, que é o maior motor de inserção das culturas locais no mercado global (MARTín-BARBERO, 2002). Mediadas pela tecnologia e pelos meios de comunicação, as culturas regionais e nacionais são difundidas pelo globo, causando uma revolução nas identidades.

No que tange às identidades culturais, a globalização tem produzido diferentes resultados. De um lado tem-se uma cultura global proliferando-se, com padronização de produtos, gostos, formas de pensar, gerando uma identidade global. De outro, um revival das culturas locais - e até nacionais em muitos países - , como movimentos fortes pela defesa do direito de se representar. Propiciada pelos meios de comunicação e pelas tecnologias da informação e com o recuo da ação dos Estados na manutenção da coesão, a partir da cultura e identidade nacionais, as culturas regionais vão ganhando espaço, sendo difundidas, e uma pluralidade de novas identidades vão sendo construídas e postas em cena, especialmente por meio das redes comunicacionais.

Nesse movimento, as comunidades vão buscar no passado as referências para a reafirmação de uma identidade, ancoradas na memória e a partir da etnia, do gênero, da sexualidade, da classe e do pertencimento a um território. Mas acabam por criar novas identidades, como forma de resistência à cultura de massa global e uma reação ao processo desenfreado de globalização, uma tentativa de reafirmação do controle sobre a vida. Em alguns casos, esses processos estão longe de ser traquilos, por isso uma dinâmica de causa e conseqüência resultam em movimentos políticos, como os separatistas, o fundamentalismo religioso (CASTELLS,1999, p. 94).

\section{TELEJORNALISMO E CONSTRUÇÃO DE IDENTIDADES}

Na sociedade ocidental, de um modo geral, os meios de comunicação, desde seu desenvolvimento, têm tido papel fundamental na formação das identidades. Jornais e novelas, cinema, rádio e televisão são meios técnicos e discursivos para representação dos territórios e populações, especialmente as nacionais. Na América Latina, a mídia e o Estado fizeram uma aliança que propiciou a consolidação ambos. A Rede Globo é o exemplo disso no Brasil. Aliada ao governo militar, nos anos 1960 e 70, teve as condições materiais para sua expansão e, em contrapartida, forneceu ao regime difusão com alcance em quase todo território para um projeto de identidade nacional.

Através dos discursos que faz circular, a mídia é quem dá visibilidade às culturas regionais nos mercados nacionais e internacionais, mas também sustenta movimentos culturais identitários de caráter regional acabando por (re)construir identidades. Os grupos querem o direito de construir sua própria imagem (MARTíN-BARBERO, 1997), e a mídia quer - novo que lhe garanta a audiência, numa lógica de mercantilização da etnia, de representação da diferença que possa ser comercializável e que sofre bricolagens conforme as imposições do mercado. E essas comunidades imaginadas são formadas a partir dos meios de comunicação, que são as referências de mundo para boa parte das pessoas.

Porém quando a mídia dá espaço para culturas regionais, geralmente o faz numa perspectiva comercial, como produto vendável (MARTíN-BARBERO, 2002). Há uma seleção do que terá espaço e de como estas culturas serão construídas. Fatalmente, há exclusão na construção de determinados discursos sobre determinada cultura e identidade. Certos sentidos irão predominar em detrimento de outros. Nesse caso, são sentidos gerados a partir do investimento nesse processo, no que há de mais exótico e excêntrico acerca das 
manifestações culturais, uma vez que a escolha e o tratamento dos assuntos se move, muitas vezes, pela sua mercantilização.

É importante considerar que toda produção de conteúdo da mídia é produção de discurso, ou seja, são construções simbólicas determinadas, leituras possíveis da realidade, que se transformam em discurso para a sociedade. Discursos que tem um local de produção, sujeito às regras do gênero narrativo, às condições técnicas e aos processos de produção, à legislação da área, à cultura profissional, aos interesses políticos e econômicos da empresa que a produz.

Os discursos resultantes desses processos constituem o que falam, têm força de verdade, marcam. No caso de um determinado território - como o Rio Grande do Sul e suas regiões - o modo como é construído num telejornal como o Jornal Nacional pode gerar conseqüências como a solidificação de representações positivas ou negativas sobre possibilidades de investimentos, de geração de renda e de emprego, de instalação de projetos empresariais, tomando-se apenas o aspecto econômico.

No que diz respeito à superestrutura, como agente simbólico, o jornalismo de televisão tem desempenhado um papel estratégico desde as primeiras transmissões das emissoras na construção da credibilidade do veículo e na conquista de sua legitimidade como agente formador da opinião pública, especialmente por seu compromisso com a retratação "fiel" dos acontecimentos. O telejornal é o responsável, dentro da grade de programação de uma Tv, na produção e apresentação de notícias, e como tal, apresenta-se como o porta-voz dos acontecimentos por meio dos quais os telespectadores pensam tomar conta dos principais fatos e notícias que se sucedem no dia.

\begin{abstract}
Os telejornais são produtos de informação de maior impacto na sociedade contemporânea e as principais fontes de informação para maioria da população brasileira. Uma das principais características da linguagem dos noticiários de Tv é garantir a verdade aos conteúdos dos discursos e também a própria credibilidade do enunciador. Produzem sentidos que resultam numa pretensa objetividade e no mito da imparcialidade. Os textos provocam efeitos de realidade. E as construções dos enunciados jornalísticos se confundem com o real porque os personagens são reais e a matéria-prima da produção são os fatos sociais (BECKER, 2004, p. 9).
\end{abstract}

Assim como boa parte da produção das emissoras, os telejornais são produzidos em rede, de forma verticalizada, cujo controle fica na cabeça de rede, expressão utilizada para indicar a sede da emissora. Isso, somado às características dos gêneros noticiosos televisivos, parece resultar num jornalismo que acaba por investir nos estereótipos por não dar conta das nuanças e sutilezas das diversidades regionais. Ou seja, o sistema operacional racionalista tende a simplificar as diferenças na sua prática diária quando da concepção da notícia, do tratamento da pauta e da edição da reportagem. Com isso, no caso do Brasil, tende a se apresentar um país com representações convencionalmente estabelecidas sobre as suas regiões, baseadas nas identidades oficiais, nos elementos culturais mais conhecidos e tomados como os caracterizadores de regiões, essas muito mais plurais do que essas representações podem abarcar.

A operação em rede, para Williams $(1990$, p.13) se estabelece como o próprio fundamento da lógica da tecnologia de radiodifusão, determinando o sentido do fluxo de informação interposto entre a cabeça de rede e as regiões. E é esse fluxo, como se disse, 
posto em uma relação vertical e padronizada que não permite dar conta a contento das diversidades regionais especialmente porque, para além do acordo firmado entre a emissora cabeça de rede e suas afiliadas, esta, ao centralizar as decisões, exerce poder em relação às TVs regionais. Segundo Kurth (2006, p. 91), esta "hierarquia do nacional sobre o local limita a autonomia das regiões distantes do Sudeste de se auto-representarem culturalmente.

Assim como os horários obrigatórios são determinados pela emissora cabeça de rede, o padrão das produções também segue determinações convenções. Por conta disso, Ehá implicações na questão nos discursos e sentidos gerados e na(s) identidade(s) cultural(is) construídas a partir deles:

O conceito de operação de rede envolve mais do que um grande número de emissoras, próprias e afiliadas, sob a mesma bandeira. Ele pressupõe uma operação sincronizada, exibição conjunta e simultânea da mesma programação, mesma linha editorial dos programas jornalísticos e regras de comercialização idênticas em todas as emissoras. Tudo trabalha para a eficiência do negócio televisivo. Nem sempre os interesses locais e nacionais são os mesmos, mas, na programação em cadeia, o nacional se impõe sobre o regional e o local. Esta produção de conteúdos uniformes, em um país de dimensões continentais como o Brasil, pode ter conseqüências para a autorepresentação das culturas regionais (KURTH, 2006, p. 91).

Um dos riscos mais iminentes na cobertura jornalística feita a partir dos moldes estabelecidos entre a Rede Globo e suas afiliadas diz respeito ao que chama de "estigmas folclorizantes". A produção jornalística da TV precisa, portanto, atender às demandas da própria prática de redação e às da audiência, muitas vezes, espetacularizando e banalizando os fatos, transformando as particularidades regionais em caricaturas. Neste sentido, como diz Kurth (2006, p.92), a produção emitida de um único centro retira dos diferentes grupos sociais a possibilidade de construção de suas próprias representações.

Evidencia-se, neste contexto, como de fato a mídia trabalha pela fragmentação das identidades na contemporaneidade. E a televisão, sobretudo, o faz pela sua linguagem fragmentada, que mistura acontecimentos do local e do global, do presente e do passado e uma estrutura narrativa de microrrelatos, pela desagregação social que promove, pela privatização da experiência de recepção que oferece (MARTíN-BARBERO, 1997). E, a partir da multiplicidade de relatos que disponibiliza, desconectados, descontextualizados em sua maioria, a Tv e sua linguagem não propiciam o relato unificador como, em certo momento histórico fez, pelo discurso da identidade nacional.

Também Priolli (2000) chama atenção para os efeitos do jornalismo em dimensões nacionais:

A "identidade nacional", portanto, ou a visão que os brasileiros têm de si mesmos e do país, passou a ser mediada fortemente pelo ponto de vista das duas maiores metrópoles. Consolidou-se a idéia de um centro dinâmico, avançado e cosmopolita - o eixo Rio-São Paulo - em contraste com uma periferia atrasada, conservadora e provinciana. (PRIOLLI, 2000, p.19). 
Também Kurth chama atenção para um efeito de homogeneização dos processos e produtos produzida pelos telejornais em função da necessidade de unicidade que a ação em rede demanda e que resulta naturalizada por conta da força legitimadora do jornalismo de televisão, e ainda de uma hierarquização do nacional sobre o regional:

No caso das redes, a representação de unidade parece tentar naturalizar a sobreposição dos aspectos internacionais e nacionais ante as questões regionais, para justificar ou mascarar a lógica mercantil da produção de informação. Ao mesmo tempo reforça a integração do indivíduo em uma sociedade aberta e globalizada. A estratégia segue uma construção ideológica de representar os acontecimentos internacionais e nacionais como se "naturalmente" fossem mais importantes ou essenciais à vida em comunidade do que aqueles locais. A naturalização é a evidência de como funcionam os códigos ideológicos na produção de sentido para constituir um "senso comum" na sociedade. (KURTH, 2006, p. 97).

As características dos gêneros jornalísticos televisivos, em que o tempo e a tecnologia são elementos fundamentais no processo produtivo, os tornam locais férteis de produção de estereótipos, padronizações, homogeneizações, espaço para os discursos do senso comum e do establishment. Especialmente em programas como o Jornal Nacional, com características massivas e em televisão aberta. Por isso, dificilmente consegue dar conta da pluralidade de um território, especialmente num programa, como é o caso do telejornal, que precisa apresentar uma realidade nacional de um país das dimensões do Brasil.

\section{JORNAL NACIONAL E O RIO GRANDE DO SUL}

O Jornal Nacional, dentre os quatro telejornais diários da Rede Globo6, foi o primeiro a operar em rede nacional no país. De forma ininterrupta, está desde 1969 no ar e se transformou, ao longo deste período, num dos telejornais com maior audiência no horário nobre. O programa conquistou credibilidade, tornando-se sinônimo para a grande maioria das pessoas do próprio conceito de telejornalismo, em que pese a imagem de representante oficial dos governos a ele vinculada. Além disso, é importante registrar que o telejornal se mantém líder de audiência e um ícone importante do jornalismo de televisão, embora essa audiência tenha sofrido algumas quedas a partir da década de 1990 por uma série de fatores, entre eles a chamada era da multiplicidade da oferta7 na TV.

Toda história, aliás, do Jornal Nacional, o referencia como um grande marco na sociedade brasileira. A apresentação do telejornal ao país pela Rede Globo foi um grande

6 Atualmente, a Rede Globo mantém os telejornais Bom Dia Brasil (manhã), Jornal Hoje (início da tarde), Jornal Nacional (noite, por volta de 20h20min) e Jornal da Globo (final da noite/início da madrugada).

7 Segundo Piccinin (2007), a era da multiciplicidade da oferta produziu uma das alterações mais importantes do cenário televisivo brasileiro a partir da década de 90. Juntamente com a Internet, a TV paga vai constituir o cenário da oferta múltipla e tornar-se responsável pela progressiva queda dos índices de audiência da TV aberta nesse período, por conta do deslocamento do segmento culturalmente sofisticado dos telespectadores - classes A e B - para as emissoras de sinal fechado. 
acontecimento por oferecer-se como o programa "integrador" de um Brasil novo (BORELLI e PRIOLLI, 2000). Teve forte apoio financeiro e técnico do governo militar nos anos de 1970, que tinham interesse na integração nacional e nas comunicações como sustentáculos ideológicos dos seus governos.

O posicionamento dos telejornais da Rede Globo, e entre eles o Jornal Nacional, também resulta da própria posição da emissora e do grupo do qual fazem parte, as Organizações Globo8. O sistema de teledifusão da Rede Globo conta com cinco emissoras próprias e 121 emissoras afiliadas no país, cobrindo a quase totalidade dos municípios brasileiros (BONNER, 2009). A Rede Globo começou a se expandir em 1972, tendo como objetivo consolidar a programação no país e, ao mesmo tempo, estabelecer relações, especialmente econômicas, nas diferentes regiões e estados. Aproveitou o momento tecnológico, político e econômico que exigia inovação, seguindo tendência internacional de uso das tecnologias de microondas e satélites geradores de novos mapas de cobertura.

Salomão (2006) diz que a proposta de regionalização das tevês atende a várias demandas ao mesmo tempo. Todas vinculadas primeiramente a uma ordem econômica. Segundo a autora, as emissoras regionais tornam a audiência mais próxima das audiências na medida em que os conteúdos reafirmam a marca. Por outro lado, são também negócios que visam o crescimento econômico-financeiro fora do eixo das metrópoles, em busca das verbas publicitárias. E neste sentido, as emissoras regionais servem também aos próprios anunciantes que passam a investir em propagandas localizadas.

Assim, depois de se fortalecer nas capitais, o objetivo da Rede Globo foi se expandir pelo país, para além das regiões metropolitanas do eixo Rio de Janeiro-São Paulo. O projeto de regionalização ganhou impulso com a implantação no seu organograma de um setor específico para atender as suas afiliadas (FERNANDES, 1996). A operação se deu por meio da incorporação de afiliadas regionais e da relação via o estabelecimento de uma rede axiomática - network - constituída da cabeça de rede e suas emissoras afiliadas. A cabeça de rede opera a partir de um ponto central que controla a emissão, retransmitindo a programação verticalmente e recebendo produção mediante pedidos previamente feitos à sua afiliada.

As empresas afiliadas retransmitem a maior parte da programação para uma área de abrangência, ao mesmo tempo em que inserem, nesta programação, produção local, devidamente negociada em horários, duração e dias estipulados pela cabeça de rede, no caso a Rede Globo. Assim, em última análise, o gerenciamento das necessidades de cobertura, o julgamento sobre o que é notícia e a forma de tratamento adequada são feitos pela cabeça de rede, muitas vezes distante e sem um conhecimento preciso das múltiplas e variadas realidades existentes num país como o Brasil e seus estados e regiões.

E nas regiões, o quadro nacional se repete na relação entre as cabeças de rede e suas praças. No Rio Grande do Sul, por exemplo, a emissora afiliada, a RBS TV, pertencente ao

8 As Organizações Globo são conduzidas por meio da holding Globopar. Segundo Bolaño (2004), juntamente com o Serviço de Televisão Aberta oferecido pela Rede Globo, a Globopar administra também Serviços de Televisão Paga, Programação de Televisão Paga, Serviços de Telecomunicações, Imobiliária, Publicação, Fonografia, Sistema Globo de Rádio (quinze estações), CBN - Central Brasileira de Notícias (cinco estações próprias e dezesseis afiliadas) e a Infoglobo (jornais $O$ Globo e Extra), constituindo assim um importante oligopólio nacional. 
grupo multimídia Rede Brasil Sul de Comunicações - $\mathrm{RBS}^{9}$, é a emissora cabeça de rede no estado e fica localizada em Porto Alegre. A partir dela, se dá a relação com as 11 praças distribuídas pelo estado10, que operam por meio de um mapa de cobertura que contempla, numa regionalização própria, todo território em que seu sinal é captado, ou seja, todo estado. As praças estão localizadas em municípios de médio porte (geralmente os que concentram maior população, sistemas de serviço público e privado e renda da região), e dessas praças com suas sucursais, localizadas em municípios também de médio porte da mesma região da praça (porém de menor população, oferta de serviços e renda em relação aos municípios sede da praça).

A relação de hierarquia entre cabeça de rede e praça e entre praça e sucursal reproduz o modelo ditado pela Tv Globo em relação às suas afiliadas. Desses diferentes níveis de poder, geram-se várias conseqüências. Uma delas é a tendência da cobertura jornalística privilegiar os municípios onde estão sediadas as praças e as sucursais, tanto por uma questão infra-estrutural, como por um entendimento da cultura jornalística da relevância desse município em relação aos demais. Outra consequência é o tipo de representações que essa situação gera, reforçando esses municípios como hegemônicos econômica, política, social e culturalmente na região e todas as implicações que isso pode gerar.

É importante lembrar que é a afiliada quem produz e envia à Rede Globo a maior parte das notícias da sua área de cobertura para a programação nacional. Sendo assim, essas representações não só se reproduzem nas regiões das praças e no estado, como nacionalmente e, muitas vezes, até internacionalmente, porque a Rede Globo mantém canais internacionais (Globo Internacional) nos quais se reproduz a programação veiculada no Brasil com algumas pequenas inserções produzidas no exterior.

A RBS é considerada uma das afiliadas de maior sucesso da Rede Globo. A parceria entre as emissoras se deu nos anos 70, período também de formação da RBS como rede no Rio Grande do Sul, partindo de jornais e rádios que já possuía, incorporando a televisão. De forma semelhante à Globo, seu bom desempenho em termos de crescimento ao longo das décadas e hegemonia no Rio Grande do Sul (bem como em Santa Catarina), se deve principalmente pela valorização de um padrão de qualidade técnica da programação, com investimento nas novas tecnologias e a contínua ênfase na programação regional, que inclui em seus limites geográficos os traços culturais e o tamanho de cada mercado das regiões de Santa Catariana e Rio Grande do Sul. A programação da RBS TV é composta basicamente por telejornais locais, por programas esportivos, programas de variedade e um crescente espaço para a ficção.

9 A Rede Brasil Sul de Comunicações - RBS - é o grupo que possui a afiliada responsável por retransmitir o sinal da Rede Globo nos estados de Santa Catarina e Rio Grande do Sul, a RBS TV. Atualmente, é o maior conglomerado regional do Brasil e um dos maiores nacionais. Integram a RBS, nos dois estados, sete jornais diários, 24 estações de rádio AM e FM, três portais de internet, dezoito emissoras de televisão afiliadas, duas emissoras de TV locais denominadas comunitárias e um canal nacional voltado para o agronegócio. Outros empreendimentos do grupo incluem gravadora de discos, empresa de distribuição, produtora de vídeo, assessoria em marketing para jovens e organização de eventos, além de uma fundação para ações de responsabilidade social. Apesar de trocarem programação e pertencerem ao mesmo grupo, a RBS TV do Rio Grande do Sul e a de Santa Catarina estabelecem uma rede própria em cada estado, sendo a sede de cada uma localizada, respectivamente, em Porto Alegre e em Floriapópolis. (REDE BRASIL SUL DE COMUNICAÇÃO, 2012)

10 As praças são: RBS TV Caxias do Sul, RBS TV Passo Fundo, RBS TV Erechim, RBS TV Cruz Alta, RBS TV Santa Rosa, RBS TV Uruguaiana, RBS TV Bagé, RBS TV Santa Maria, RBS TV Santa Cruz do Sul, RBS TV Pelotas, RBS TV Rio Grande. As informações vêm do site http://comercial.redeglobo.com.br/atlas2004/index.php. 
A RBS TV é a emissora líder em horas de produção entre todas as afiliadas da Globo. No caso da RBS no Rio Grande do Sul, a empresa possui, em Porto Alegre, um núcleo de jornalistas responsáveis por gerenciar esta negociação com a Rede Globo diariamente. E essa negociação acontece inclusive com a equipe do Jornal Nacional. Ou seja, quem conduz a produção das notícias sobre as regiões do Rio Grande do Sul que irão para a cadeia nacional é um núcleo da RBS dedicado especialmente à produção para os telejornais da Rede Globo, localizado em Porto Alegre, na cabeça da rede da RBS TV, chamado Núcleo Globo. Esse núcleo, por sua vez, se vale da rede de emissoras que a RBS mantém no Rio Grande do Sul para "colher" pautas e notícias e reportagens finalizadas para a TV Globo. E essas afiliadas são também responsáveis por retransmitir a programação da Rede Globo na maior parte das vinte quatro horas do dia, recebendo, em troca, um tempo para veicular programação própria na área de veiculação do seu sinal.

Vê-se que esse sistema de afiliamento permite à emissora cabeça de rede, no caso da Rede Globo um controle de programação e, em última instância também territorial como diz Rosario (2008). A tecnologia serve à delimitação de circunscrição de poder, neste caso a serviço das demandas do mercado. Para a autora, a psicosfera traz a idéia de um Brasil oficial, através da criação de uma identidade nacional, mesmo em confronto com o Brasil real, neste caso plural, diverso, multifacetado. Por isso, a integração nacional é antes de tudo a integração de mercados que gerando uma reprodução de hábitos, costumes e valores do eixo Rio-São Paulo para o restante do país através da programação nacional.

A constituição da idéia de unidade rigidamente controlada pelo Padrão Globo de Qualidade que requer a atuação em rede se dá na relação entre a cabeça de rede e as afiliadas por meio de ações continuamente reforçadas entre ambas. Segundo Pachler (2006) ainda que as emissoras afiliadas não operem a partir de um manual, essa formatação padronizada às matérias que contribui para a redução das diferenças e multiculturalidades das notícias regionais, neste caso, oriundas do Rio Grande do Sul seguem alguns movimentos.

Além do Núcleo Globo que opera na RBS TV, conforme já descrito, e que tem tanto a responsabilidade de oferecer material à cabeça de rede, quanto receber e operacionalizar as demandas aqui no estado, a Rede Globo está autorizada contratualmente, a escolher, em comum acordo com a afiliada, o gerente de jornalismo da emissora. Para a autora, isso garante que esteja no cargo um profissional em total sintonia com o Padrão Globo, evitando o desrespeito aos itens acordados no aditivo de programação, ao fim, à linha editorial. Ainda, três outros momentos estabelecidos, o Encontro das Praças, o Uniglobo Virtual e as reuniões de caixa, amarram a relação de padronização da forma e dos conteúdos. O primeiro é uma integração entre profissionais da cabeça de rede e das afiliadas; o segundo, treinamentos para os funcionários feitos pela Globo sobre reportagem, edição de texto e imagem, entre outros; e o terceiro, reuniões diárias à distância com ofertas e demandas de pauta

Além disso, Pachler (2006) lembra oportunamente que os próprios repórteres sentemse estimulados a fazer a notícia se enquadrar no formato padrão, uma vez que é meta aparecer na rede e especialmente no Jornal Nacional. O profissional internaliza a linha editorial, naturalizando as práticas produtivas e editoriais, inclusive com vistas a sua manutenção e ascensão dentro do grupo de comunicação. Como a tarefa não é fácil, porque é fruto de uma disputa de oferta das 121 emissoras afiliadas, nessa corrida, todo esforço é válido para tornar-se um repórter rede que tem além do prestígio, o salário mais que duplicado. E no mesmo sentido, as emissoras afiliadas não vêem o Padrão Global como uma 
demanda sacrificiosa e, sim, a crença de que ao se pautarem por estas orientações estão fazendo o jornalismo da melhor maneira e com garantia de qualidade.

\section{CONSIDERAÇÕES FINAIS}

A prática jornalística, em função da organização das rotinas produtivas, dos negócios de mídia e dos gêneros, limita as possibilidades de representação dos territórios e das populações. O Jornal Nacional se debate diariamente entre a tentativa de "noticiar" um todo sobre o Brasil (e o mundo, pois tem espaço para notícias internacionais) em seus 35 minutos diários de programação. Ao escolher determinados acontecimentos para eleger como notícia e certos ângulos de tratamento desses, constrói sentidos e identidades sobre o Brasil e suas partes.

Nesse cenário, o Rio Grande do Sul ocupa condição periférica do ponto de vista infraestrutural, tanto do aspecto geopolítico, quanto na geografia da mídia nacional, o que implica num menor conhecimento sobre a realidade do estado por parte da produção do Jornal Nacional. Por outro lado, tem a maior afiliada da Tv Globo, a RBS TV, que como emissora e pertencente a um dos maiores grupos de comunicação regional do país, de certa forma, faz um contraponto nesse jogo de forças desigual. Ao se organizar num grupo forte, a RBS tem condições de disputar nessa arena espaços para sua produção, muito embora tenha que se sujeitar a certas regras, como os padrões e formatos de produção e à linha editorial ditada pela Tv Globo. Nesse embate, a tendência é que a RBS Tv, muito provavelmente, busque no material enviado à cabeça de rede corresponder às expectativas editoriais dessa de modo a conquistar mais espaços na grade do Jornal Nacional, bem como de outros telejornais.

Desta forma, percebe-se que as conseqüências que essa 'geografia' ocasiona em termos de construção de identidade sobre o Rio Grande do Sul ou qualquer outro estado ou região fora do eixo de concentração nacional da mídia tendem às construções consensuais, geralmente recheadas de estereótipos e folclorizações. E que essas, por sua vez, em última análise, atuam nos imaginários das coletividades - tanto no espaço regional, como no nacional - constituindo-se, muitas vezes, em resistências e entraves ao processo de desenvolvimento e emancipação dessas comunidades.

\section{REFERÊNCIAS}

ATLAS DE COBERTURA. Disponível em: <http://comercial.redeglobo.com.br/atlas2004/ index.php>. Acesso em 06/01/2011.

BECKER, Beatriz. A linguagem do telejornal. Rio de Janeiro: E-papers, 2004.

BOLÃNO, Cesar. Mercado Brasileiro de Televisão. São Paulo: Aracaju, 2004.

BONNER, Wiliam. Jornal Nacional: modo de fazer. Rio de Janeiro: Globo, 2009.

BORELLI, Silvia H. S.; PRIOLLI, Gabriel (Org.). A Deusa ferida: por que a Rede Globo não é mais a campeã absoluta de audiência. São Paulo: Summus, 2000. 
CANCLINI, Néstor Garcia. Culturas híbridas. Estratégias para entrar e sair da modernidade. São Paulo: Edusp, 1997.

CASTELLS, Manuel. O poder da identidade. São Paulo: Paz e Terra, 1999. (A sociedade em rede: economia, sociedade e cultura, 2 ).

EM DEZ ANOS, "JORNAL NACIONAL" PERDE UM EM CADA QUATRO EXPECTADORES. Disponível em: <http://www1.folha.uol.com.br/ilustrada/855055-em-dez-anos-jornalnacional-perde-um-de-cada-quatro-telespectadores.shtml>. Acesso em 18/01/2011.

FELIPPI, Ângela; NECCHI, Vítor (Org.). Mídia e identidade gaúcha. Santa Cruz do Sul: EDUNISC, 2009.

FERNANDES, Rosimeire Ap. de Castro. UNIVERSIDADE METODISTA DE SÃO PAULO. Programa de Pós Graduação em Comunicação Social. Depois dos comerciais: o compromisso do telejornal regional com o mercado. 1996. Dissertação (Mestrado), São Bernardo do Campo: IMS, 1996.

HALL, Stuart. Identidade cultural e diáspora. Revista do Patrimônio Histórico Nacional. Rio de Janeiro, n. 24, p. 68-76, 1996.

A centralidade da cultura: notas sobre as revoluções culturais do nosso tempo. Cultura, Mídia e Educação - Educação \& Realidade, Porto Alegre, v. 22, n 2, p 15-46, jul./dez. 1997.

A identidade cultural na pós-modernidade. Rio de Janeiro: DP\&A, 1999.

Quem precisa da identidade? In: SILVA, Tomaz Tadeu da (org). Identidade e diferença. Petrópolis, RJ: Vozes, 2000, p. 103-133.

. Da Diáspora: Identidades e Mediações culturais. Belo Horizonte: UFMG; Brasília: Unesco, 2003.

KURTH, Estela. Representação das emissoras regionais na grade nacional de programação das redes de televisão. IN: Estudos em Jornalismo e Mídia. Vol. III No 1 - 10 semestre de 2006. Disponível em <http://posjor.ufsc.br/public/docs/75.pdf>. Acesso em 08/01/2010.

LARRAIN, Jorge. El concepto de identidad. Revista FAMECOS, Porto Alegre, n. 21, p. 30-42, ago. 2003.

MATTELART, Armand. Comunicação-mundo: história das idéias e das estratégias. Petrópolis, RJ: Vozes, 1994.

MARTÍN-BARBERO, Jesús. Tecnicidades, identidades, alteridades: des-ubicaciones y opacidades de la comunicación en el nuevo siglo. Revista Dia-Logos de la Comunicación. México: FELAFACS, n. 64, p. 8-23, 2002.

MARTÍN-BARBERO, Jesús. Globalización comunicacional y descentramiento cultural. Revista Dia-Logos de la Comunicación, n. 47, p. 27-41, 1997. 
ORTIZ, Renato. Cultura brasileira e identidade nacional. São Paulo. Brasiliense, 1986. . Mundialização e cultura. São Paulo: Brasiliense, 1994.

PACHLER, Lilian. PONTIFÍCIA UNIVERSIDADE CATÓLICA DE SÃO PAULO. Programa de Pós Graduação em Comunicação Social. Televisões regionais: O processo entre Rede Globo e afiliadas. 2006. 123f. Dissertação (Mestrado) - Pontifícia Universidade Católica do Rio Grande do Sul, 2006.

PICCININ, Fabiana. PONTIFÍCIA UNIVERSIDADE CATÒLICA DO RIO GRANDE DOSUL. Programa de Pós-Graduação em Comunicação Social. "Veja a seguir": a transição do telejornal. Entre a linha de montagem e a rede. 2007. 241f. Tese (Doutorado) - Pontifícia Universidade Católica do Rio Grande do Sul, 2007.

PIERUCCI, Antônio Flávio. Ciladas da diferença. São Paulo: USP-Editora 34, 1999.

PRIOLLI, Gabriel. Antenas da Brasilidade. In HAMBURGER, Esther (org.). A TV aos 50: a televisão brasileira no seu cinqüentenário. São Paulo: Fundação Perseu Abramo, 2000.

REDE BRASIL SUL DE COMUNICAÇÕES. www.rbs.com.br. Acesso em 19/03/2012.

ROSARIO, Eliane Regina Munhoz. As afiliadas da Rede Globo de Televisão no território brasileiro. Ateliê Geográfico. Goiânia, v. 2, n. 4, agos/2008 p.119-137.

SALOMÂO, Virgínia. Rede de televisão e regionalização da produção audiovisual no Brasil: o caso EPTV. UNESCOM - Congresso Multidisciplinar de Comunicação para o Desenvolvimento Regional. São Bernardo do Campo - SP . Brasil - 9 a 11 de outubro de 2006. Universidade Metodista de São Paulo. Disponível em <http://encipecom.metodista.br/mediawiki/ images/6/65/GT2-_REGIOCOM-_20-_Rede_de_Televisao-_Virginia.pdf>. Acesso em 27/06/2010.

WILLIAMS, Raymond. Television - Technology and Cultural Form. London: Routledge, 1990.

Culture is ordinary. In: GRAY, Ann; MCGUIGAN, Jim. (Org.). Studyine culture. London: Arnold, 1993, p. 5-14.

WOODWARD, Kathyn. Identidade e diferença: uma introdução teórica e conceitual. In: SILVA, Tomaz Tadeu da (Org.). Identidade e Diferença. Petrópolis, RJ: Vozes, 2000, p. 7-72. 